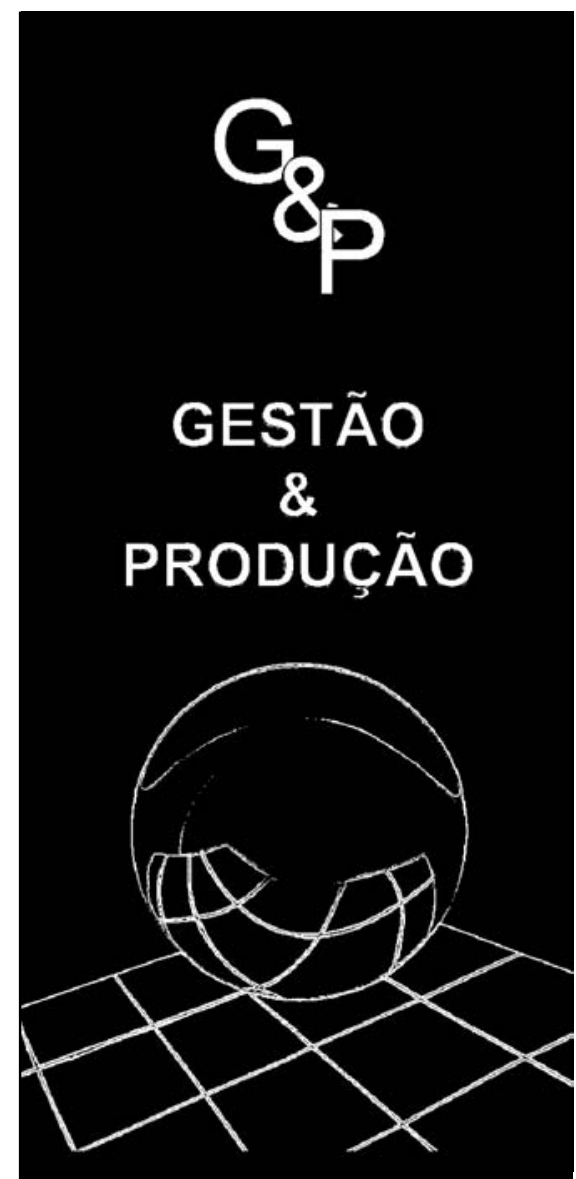

v.8, n.1, p.100-111, abr. 2001

\section{IMPLANTAÇÃO DO HACCP NA INDÚSTRIA DE ALIMENTOS}

\author{
Veruschka Franca de Figueiredo \\ Escola Politécnica da USP - Engenharia de Produção \\ Pedro Luiz de Oliveira Costa Neto \\ Escola Politécnica da USP - Engenharia de Produção \\ Universidade Paulista - Engenharia de Produção \\ Faculdade Tancredo Neves - Engenharia de Produção
}

\title{
Resumo
}

O conceito da Análise de Perigos e Pontos Críticos de Controle (APPCC) é uma abordagem sistemática para garantir a segurança do alimento. O método é baseado em vários princípios diferentes de detecção direta ou indireta de contaminação. O objetivo é controlar a segurança do alimento analisando os perigos em potencial, planejando o sistema para evitar problemas, envolvendo os operadores em tomada de decisão e registro das ocorrências. O conceito da HACCP (APPCC) deveria ser aplicado em conjunto com as Boas Práticas de Fabricação. Este artigo discute a importância da HACCP (APPCC) na Indústria de Biscoito e que tipo de contaminação é o ponto fraco neste produto. A experiência indicou que existem diversos problemas iniciais na implementação da HACCP, contudo benefícios tangíveis podem ser alcançados a partir da redução das reclamações do consumidor.

Palavras-chave: HACCP, APPCC, alimento, segurança e perigo.

\section{Introdução}

$\mathrm{O}$ termo qualidade há muito tempo já faz parte do vocabulário de muitas pessoas, mas como defini-lo de forma a atingir toda a dimensão do seu significado? A qualidade envolve muitos aspectos simultaneamente e sofre alterações conceituais ao longo do tempo (PALADINI, 1996).

Alguns conceitos de qualidade foram estrutu- 
rados tendo a satisfação do consumidor como o elemento principal:

- "Qualidade é a adequação ao uso" (JURAN \& GRYNA, 1993).

- "Qualidade é a condição necessária de aptidão para o fim a que se destina" (Organização Européia de Controle da Qualidade, 1972 apud PALADINI, 1996).

- "Qualidade é o grau de ajuste de um produto à demanda que pretende satisfazer" (JENKINS, 1991 apud PALADINI, 1996).

É interessante ressaltar que esses conceitos correlacionam os interesses da empresa com o atendimento às necessidades do cliente. Logo, para que se tenha uma contínua evolução da qualidade, deve-se saber o quanto os consumidores estão satisfeitos com os produtos que estão adquirindo.

A qualidade hoje é uma vantagem competitiva que diferencia uma empresa de outra, pois os consumidores estão cada vez mais exigentes em relação à sua expectativa no momento de adquirir um determinado produto. Logo, as empresas que não estiverem preocupadas com esta busca pela qualidade poderão ficar à margem do mercado consumidor.

Quando se fala em qualidade para a indústria de alimentos, o aspecto segurança do produto é sempre um fator determinante, pois qualquer problema pode comprometer a saúde do consumidor. É de se esperar, pois, que as boas empresas que atuam nesse ramo de atividade tenham algum sistema eficaz para exercer esse controle, um dos quais é discutido neste artigo.

Julgamos que, com isso, possamos contribuir para a discussão do tema, pois, se no Brasil há empresas líderes do ramo de alimentos que estão implementando sistemas de gerenciamento da qualidade, ainda existe um grande número de outras empresas que não aplicam ferramentas para garantir a qualidade de seus produtos.

\section{HACCP}

A HACP (Hazard Analysis and Critical Control Points) ou APPCC é a sigla para análise de perigos e pontos críticos de controle, um sistema baseado numa forma sistemática de identificar e analisar os perigos associados com a produção de alimentos e definir maneiras para controlá-los (STRINGER, 1994), apresentado a seguir.

\section{a) Histórico}

No início de 1970, uma série de fatos aconteceu nos Estados Unidos em relação a problemas relacionados com a segurança dos produtos que estavam sendo consumidos, originando o seguinte questionamento: "Como em 1969 os EUA foram capazes de enviar o homem à lua e em 1970 ainda temos incidentes que comprometem a segurança dos nossos produtos?" A resposta encontrada foi que seria necessário promover uma mudança na forma de desenvolver e produzir alimentos, tornando-a mais científica e controlada (BENNET \& STEED, 1999).

O termo alimento seguro é um conceito que está crescendo na conjuntura global, não somente pela sua importância para a saúde pública, mas também pelo seu importante papel no comércio internacional (BARENDSZ, 1998). Este sistema foi utilizado pela primeira vez, nos anos 60 , pela Pillsburg Company, junto com a NASA (National Aeronautics and Space Administration) e o U.S. Army Laboratories em Natick, com o objetivo de desenvolver um programa de qualidade que, utilizando algumas técnicas, desenvolvesse o fornecimento de alimentos para os astronautas da NASA (BENNET \& STEED, 1999), sendo apresentado ao público pela primeira vez em 1971, durante a conferência nacional para proteção de alimentos, realizada nos Estados Unidos (ATHAYDE, 1999).

A legislação em segurança do alimento é geralmente entendida como um conjunto de procedimentos, diretrizes e regulamentos elaborados pelas autoridades, direcionados para a proteção da saúde pública. A HACCP foi uma ferramenta desenvolvida originalmente pelo setor privado para garantir a segurança do produto e atualmente está sendo introduzida na legislação de vários países (JOUVE, 1998). 
A partir de 14 de dezembro de 1995, todas as empresas de alimentos da União Européia deveriam ter um sistema de HACCP implementado. Este foi o resultado de diretrizes da EEC / 93-43, aprovada pelo Conselho da Europa em 14 de junho de 1993 (GRIJSPAARDT-VINK, 1994).

No Brasil, apesar de existirem alimentos com padrões de excelência comparáveis aos produzidos nos países do Primeiro Mundo, ainda existem problemas que comprometem a qualidade e apresentam riscos à saúde humana (BRANDIMARTI, 1999).

Nas pequenas indústrias, podem ser apontadas como questões ainda não resolvidas a falta de aplicação das BPF (Boas Práticas de Fabricação) (BRANDIMARTI, 1999). Apesar das BPF e do método APPCC estarem estabelecidos na legislação por meio de leis, decretos e portarias (Portarias n ${ }^{\circ} 1428 / 93$ e n $^{\circ} 326 / 97$ do Ministério da Agricultura (MA); Portarias $n^{\circ} 40$ / 98 e 46 / 98 do MA), sua aplicação apesar de notáveis exceções, é quase inexistente (BRANDIMARTI, 1999). Inicialmente, o sistema HACCP desenvolvido pela "The Pillsbury Company" consistia de três princípios (JOUVE, 1998):

- Análise de perigo e avaliação do risco;

- Determinação dos pontos críticos de controle; e

- Monitoramento dos PCC's.

A avaliação do risco levava em consideração três características (BAUMAN apud JOUVE, 1998):

- O produto contém algum ingrediente sensível?

- Há uma etapa do processo que elimina o perigo? e

- Há potencial de danos causados pelo produto?

Em 1989, expandiu-se esse processo de avaliação dos riscos para seis etapas (JOUVE, 1998):

- O produto é direcionado para o consumidor na população de alto risco?

- O produto contém ingredientes sensíveis?

- Há uma etapa que destrói os microorganismos patogênicos?
- Há possibilidade de recontaminação do produto após a etapa de eliminação dos patógenos?

- Há possibilidade do produto estragar durante a distribuição ou consumo? e

- Há um tratamento térmico final?

\section{b) Conceituação}

O conceito de HACCP permite um estudo sistemático para identificar os perigos, avaliar a probabilidade deles acontecerem durante o processamento, a distribuição ou o uso do produto e definir meios para controlá-los (ILSI, 1997).

O sistema de análise de perigos e pontos críticos de controle (APPCC ou HACCP) é um método embasado na aplicação de princípios técnicos e científicos de prevenção, que tem por finalidade garantir a inocuidade dos processos de produção, manipulação, transporte, distribuição e consumo dos alimentos. Esse conceito cobre todos os fatores que possam afetar a segurança do alimento (ATHAYDE, 1999).

As BPF são um pré-requisito para a implementação de HACCP e esse está correlacionado com a garantia da qualidade (JOUVE, 1998).

A contaminação microbiológica é conhecida como a mais ameaçadora à saúde humana; contudo, a presença de resíduos químicos também oferece grande ameaça, principalmente quando analisados os efeitos no longo prazo. Além disso, a contaminação microbiológica pode ser bastante controlada, pelas Boas Práticas de Higiene, durante o manuseio e processamento dos alimentos, enquanto a contaminação química é em geral bastante difícil de ser controlada (BARENDSZ, 1998).

Segundo o "Codex Alimentarius", o sistema de HACCP consiste em seguir os seguintes princípios (ILSI, 1997):

- Identificar os perigos e analisar os riscos de severidade e probabilidade de ocorrência;

- Determinar os pontos críticos de controle necessários para controlar os perigos identificados; 
- Especificar os limites críticos para garantir que a operação está sob controle nos pontos críticos de controle (PCC);

- Estabelecer e implementar o monitoramento do sistema;

- Executar as ações corretivas quando os limites críticos não foram atendidos;

- Verificar o sistema; e

- Manter registros.

O embasamento do sistema de HACCP tem o termo perigo como um agente nocivo, ou condição do alimento inaceitável, que pode causar algum efeito de saúde adverso. Segundo ILSI (1997) os perigos podem ser provocados por:

- A presença inaceitável de uma contaminação química, física ou microbiológica na matéria-prima, no produto semifabricado ou no produto final;

- Potencial de crescimento ou de sobrevivência de microorganismos ou de produção de substâncias químicas no produto semifabricado, no produto final ou no ambiente da linha de produção; e

- Recontaminação do produto semifabricado ou do produto final com microorganismos, produtos químicos ou corpos estranhos.

Um alimento seguro, que não cause mal à sua saúde e não ofereça dúvidas em relação à sua composição e peso, é uma das mais importantes características da qualidade que correspondem às expectativas do consumidor (BERG apud BARENDSZ, 1998).

Vários perigos podem comprometer a segurança dos alimentos, tais como:

- Microbiológico (coliforme fecal, salmonella, listeria);

- Nutricional (consumo de gordura, nível de obesidade);

- Ambiental (pesticida, metal pesado, nitrato);

- Natural (ingredientes); e

- Aditivos alimentares.

HACCP é uma técnica sistemática e racional para se prevenir a produção de alimentos contaminados, baseada em análises e evidências científicas. Representa uma atitude pró-ativa para prevenir danos à saúde e enfatizar a prevenção de problemas, ao invés de se focar no teste do produto final. Pode ser utilizado em qualquer estágio da cadeia de produção, desde a produção primária até a distribuição, e até mesmo nos locais que oferecem serviços de alimentação e em casa (JOUVE, 1998).

Entretanto, alguns dos problemas encontrados pelas pequenas indústrias na implantação dos sistemas de HACCP são: insuficiente suporte técnico, concentração de funções, disponibilidade financeira e de tempo para implementar a HACCP (KIRBY apud PETA \& KAILASAPATHY, 1995).

O "Codex Alimentarius" recomenda a seguinte sequiência para implementação do sistema de HACCP (WHO, 1997 e ILSI, 1997):

\section{Formação da equipe de HACCP}

A equipe deve ter uma formação multidisciplinar. As pessoas devem estar familiarizadas com os produtos e seus métodos de elaboração. As pessoas integrantes da equipe devem ter poder de convencimento, liderança e capacidade de multiplicação dos conceitos. O líder da equipe deve ter treinamento e habilidade suficiente em HACCP. O escopo do estudo deve ser definido, sabendo-se quais etapas da cadeia produtiva devem ser envolvidas.

\section{Descrição do produto}

Uma detalhada descrição do produto deve ser feita, incluindo sua composição química e física, o tipo de embalagem, o transporte utilizado na distribuição, as condições de armazenagem e o tempo de vida útil.

3. Identificação do uso

Deve-se identificar qual o público-alvo do produto e saber se faz parte de um segmento particular da população (bebês, idosos, enfermos, adultos, etc.).

4. Construção do diagrama de fluxo Deve-se resumir o fluxo de processo em um diagrama simplificado, que forneça um 
esboço do processo e realce a localização dos perigos potenciais identificados. É importante não negligenciar nenhuma etapa que possa afetar a segurança do alimento.

5. Confirmação no local das etapas descritas no fluxograma

Uma vez estabelecido o diagrama operacional, deve-se efetuar a inspeção no local, verificando a concordância das operações descritas com o que foi representado. Esta etapa irá assegurar que os principais passos do processo terão sido identificados e possibilitar os ajustes necessários.

6. Listar todos os perigos, analisar os riscos e considerar os controles necessários

Todos os perigos em potencial, relacionados a cada etapa do processo, devem ser identificados com base na experiência dos membros da equipe e nas informações de saúde pública sobre o produto. A análise dos riscos deverá ser feita considerando os seguintes fatores:

- Probabilidade de ocorrência do perigo e sua severidade em relação aos efeitos adversos à saúde;

- Evolução qualitativa e quantitativa da presença do perigo;

- Capacidade de multiplicação e sobrevivência dos microorganismos; e

- Produção ou permanência nos alimentos de toxinas, agentes químicos ou físicos.

Quaisquer medidas de controle existentes ou que poderiam ser aplicadas devem ser listadas. Mais de uma medida de controle pode ser necessária para controlar um perigo e mais de um perigo pode ser controlado por uma mesma medida de controle.

7. Determinar os pontos críticos de controle (PCC)

Um PCC é uma etapa na qual um controle pode ser aplicado, sendo essencial prevenir ou eliminar um perigo relativo à segurança dos alimentos, reduzi-lo ou mantê-lo em nível aceitável. Identificar os PCCs no estudo de HACCP pode ser facilitado utilizando-se uma árvore decisória, que consiste em se fazer uma série de perguntas para cada etapa de elaboração do produto (anexo 1).

Muitos pontos críticos de controle sugerem uma análise de riscos irreal, enquanto poucos PCCs identificados indicam que podem existir riscos que não foram considerados. Por isso, a etapa de identificação dos PCCs é um aspecto crítico do estudo de HACCP (BUCHANAM apud PETA \& KAILASAPATHY, 1995).

Note-se que existem algumas partes do processo ou equipamento que a empresa quer monitorar, mas não são PCCs levantados pela HACCP. Estes pontos podem ser identificados como pontos de controle (PCs) da qualidade e são controlados para evitar um desvio nos PCCs, que protegem a saúde pública. Um exemplo de PC pode ser um ímã, quando um detector de metal está colocado numa etapa posterior do processo, sendo este o PCC (BENNET \& STEED, 1999).

\section{Estabelecer limites críticos para cada PCC}

Os limites críticos são aqueles que separam os produtos aceitáveis dos inaceitáveis, podendo ser qualitativos ou quantitativos. Cada parâmetro estabelecido deve ter o seu limite crítico estabelecido, de forma a manter a visão clara das medidas de controle dos PCCs.

$\mathrm{O}$ estabelecimento desses limites deve estar baseado nos conhecimentos disponíveis em fontes como: legislação, literatura científica, dados de pesquisas reconhecidas, normas internas da empresa, etc.

9. Estabelecer um sistema de monitoramento para cada PCC

Para assegurar que as medidas de controle operem como planejado nos PCCs e detectem qualquer perda de controle, é necessário definir um sistema de monitoramento dos PCCs. Neste deve estar definido qual o procedimento de controle que deve estar associado a cada PCC. Os métodos de controle devem ser rápidos, para serem efetivos. $\mathrm{O}$ sistema de monitoração deve permitir, quando possível, que os ajustes sejam feitos antes que uma 
medida exceda os limites críticos. Medidas físicas e químicas são às vezes preferíveis a testes microbiológicos, porque podem ser levantadas rapidamente e, muitas vezes, indicam a condição microbiológica do produto.

\section{Estabelecer ações corretivas}

Ações corretivas específicas devem ser definidas para cada PCC identificado no sistema HACCP, a fim de que possam trazer o PCC sob controle, definir o que fazer com o produto que saiu enquanto o PCC estava fora de controle e descobrir porque o PCC estava fora de controle. Os desvios e procedimentos para disposição dos produtos devem estar documentados.

\section{Estabelecer procedimento de verificação}

A aplicação de métodos de verificação e auditoria, procedimentos e testes, incluindo amostragem e análises aleatórias, podem ser utilizadas para testar se o sistema HACCP está funcionando corretamente. De maneira regular ou não planejada, a informação disponível no sistema HACCP deve ser sistematicamente analisada.

\section{Estabelecer documentação e manter registros}

Os procedimentos do sistema HACCP devem estar documentados, assim como os registros das atividades de monitoramento dos PCCs, das ações corretivas relacionadas aos desvios e das modificações do sistema HACCP. Estas informações devem ser mantidas para acompanhamento e revisões subseqüentes.

\section{ISO 9000 e HACCP}

É preciso notar que o certificado ISO 9000 não garante a qualidade do produto, mas que a empresa possui um sistema de garantia da qualidade capaz de produzir produtos compatíveis com as especificações desejadas. Confundese muito este tipo de certificação com certificação de produto, estabelecendo-se uma relação direta entre ela e a qualidade final do produto (OLIVEIRA, 1999). Existe também a frequiente confusão de que a ISO 9000 garante 100\% de produtos de primeira qualidade (STRINGER, 1994).

Entretanto, a ISO 9000 serve de suporte para a implementação da HACCP e, juntos, são fundamentais para promover o sucesso da indústria de alimentos, pois suas recomendações se complementam. A HACCP é utilizada para identificar os PCCs, enquanto a ISO 9000 é usada para controlar e monitorar aspectos críticos para a qualidade.

A HACCP é focada somente no que é crítico para garantir um alimento seguro, livre de contaminações físicas, químicas e microbiológicas, que possam causar doenças ou danos ao consumidor.

Para implantar a ISO 9000, a empresa deve analisar os elementos de conformidade e definir quais atividades afetam a qualidade, definindo depois quais são os procedimentos, instruções e técnicas que devem ser empregadas para controlar essas atividades (BENNET \& STEED, 1999). Esta visão propicia que a política das empresas de alimentos evolua em direção ao conceito de alimento seguro, suportada por um eficiente sistema de gerenciamento da qualidade (BARENDSZ, 1998).

Um dos grandes problemas dos sistemas HACCP e ISO 9000 é o excesso de documentação, logo é importante ressaltar que somente se deve documentar o que é importante para a qualidade, a segurança dos alimentos e a satisfação do consumidor, além de manter sempre atualizada essa documentação. A inclusão da HACCP como apoio ao sistema de qualidade da norma ISO 9000 é a melhor opção para as indústrias alimentícias (BENNET \& STEED, 1999). A HACCP pode ser incorporada ao sistema ISO 9000 e certificada como parte dele (STRINGER, 1994).

\section{Considerações Importantes}

adoção pelo "Codex Alimentarius" do
Controcumento "Hazard Analysis and Critical
Cystem and Guidelines for its 
Application" (Sistema de Análise de Perigo e Ponto Crítico de Controle e Guia para sua Aplicação) aprovou internacionalmente a HACCP como sistema eficiente para garantir a segurança dos alimentos. Contudo, isto é o reflexo do excelente trabalho da indústria de alimentos e da comunidade científica internacional para desenvolver um método que, quando implementado corretamente, pode aumentar significativamente o controle sobre os riscos de problemas causados à saúde da população por ingestão de alimentos (JOUVE, 1998).

Um grande número de informações, matériasprimas utilizadas, transformações químicas e físicas que acontecem nas etapas de fabricação, bem como os principais tipos de contaminação inerentes ao produto, devem ser levantados para utilização da ferramenta HACCP. Estes dados nem sempre estão disponíveis e sua pesquisa deve ser considerada como uma etapa preliminar. Qualquer falha no levantamento dessas informações pode significar erros no resultado final do estudo de HACCP.

Após a aplicação da HACCP, são listados os perigos significativos para aquele processo, os limites críticos de controle e as ações corretivas a serem tomadas para minimizarem os riscos de contaminação, bem como as modificações necessárias para eliminar ou possibilitar o controle de determinados perigos.

São muito importantes os critérios a serem utilizados para determinar se existe um alto risco ou um risco moderado de ocorrer um perigo causador de doença, injúria ou dano resultante de uma falha em alguma operação. $\mathrm{O}$ excesso de pontos críticos de controle pode significar colocar no mesmo nível os pontos que influenciam na segurança do produto final e aqueles que podem ser eliminados nas etapas posteriores do processo, levando ainda a um aumento do custo do controle.

Quando se fala em indústria de alimentos, é interessante ressaltar que muitas causas de contaminação são provenientes da falta de aplicação de procedimentos de limpeza e de comportamento das pessoas que manipulam os alimentos. As Boas Práticas de Fabricação (BPF) são um conjunto de regras que definem formas ideais de fabricação, a partir de mudanças nos métodos de limpeza, comportamento das pessoas envolvidas, equipamentos e edifícios, buscando eliminar as fontes genéricas de possíveis contaminações de um produto (CARBALLIDO et al., 1994).

Dessa forma, é interessante que se tenha a aplicação das BPF antes da implementação da HACCP, pois haverá um direcionamento dos esforços para os pontos específicos de contaminação do produto. Contudo, é possível que a HACCP seja aplicada em conjunto com as BPF, desde que se tenha claramente definido as diferenças entre os riscos que podem ser controlados pelas BPF daqueles que exigem modificação no processo ou algum controle específico.

Observa-se que grande parte das contaminações é possível de ser evitada a partir da aplicação correta das BPF. Isto significa a necessidade de um grande comprometimento das pessoas envolvidas na fabricação do produto.

Portanto, seja na aplicação da HACCP ou das $\mathrm{BPF}$, a etapa de treinamento é importante para dar embasamento necessário à aplicação dos conceitos na prática, pois há uma grande exigência de mudança de comportamento das pessoas. Nesses treinamentos, devem ser mostrados de forma clara, os tipos de contaminação e o que se pode fazer para evitá-los, bem como a preocupação com os problemas que a contaminação pode causar aos consumidores.

\section{Estudo de Caso}

$\mathrm{P}$ ara ilustrar o que foi apresentado a cerca do método HACCP, será relatado um estudo de caso que se passou numa fábrica de biscoitos com aproximadamente 700 empregados.

O grupo de trabalho foi formado por quatro pessoas, sendo uma do setor de fabricação, duas da embalagem e um líder de projeto. A pessoa do setor de fabricação tinha um grande conhecimento prático de todas as etapas da fabricação de 
biscoitos, as duas pessoas da embalagem conheciam os problemas específicos da área de empacotamento, tinham conhecimentos de informática e muito interesse em desenvolver esse novo trabalho, e o líder de projeto, apesar de não conhecer especificamente o processo de fabricação de biscoitos, tinha um embasamento teórico, conhecia a aplicação da técnica de HACCP e exercia uma função empreendedora e integradora, com atuação de forma participativa, fornecedora de apoio conceitual, metodológico e tecnológico ao grupo. Todos os integrantes da equipe dedicavam tempo integral à execução desse projeto de implementação da HACCP e das BPF.

Antes de iniciar os trabalhos, o grupo recebeu do líder de projeto um treinamento para conhecer o método HACCP, assim como os conceitos das BPF. Em seguida, o grupo de trabalho, com o apoio do setor de recursos humanos, montou e aplicou todo o treinamento necessário para explicar ao restante dos empregados os conceitos de HACCP e BPF, ao mesmo tempo em que dava início no desenvolvimento dos trabalhos da seguinte forma:

- Visita do grupo aos locais do processo de fabricação, desde o recebimento das matérias-primas até a expedição do produto acabado, com o objetivo de conhecer as etapas de produção;

- Observações a respeito dos locais do processo de fabricação, com os possíveis perigos de contaminação. Nessa etapa, houve uma grande participação dos empregados desses setores, fornecendo ao grupo as informações importantes sobre a forma de trabalho, assim como sua vivência pessoal de acontecimentos que nem sempre estão documentados na empresa;

- Análise dos perigos de fabricação, para identificar quais deles seriam eliminados ou seus riscos minimizados pela aplicação das BPF;

- Detalhamento das BPF que iriam atuar nos pontos indicados no tópico anterior e montagem das instruções de trabalho (anexo 2);

- Aplicação da árvore decisória (anexo 1). Nesta etapa foi analisado o risco de contaminação após a aplicação das BPF. O resultado foi a identificação de três possíveis situações para os pontos levantados: não eram PCC, eram PCC ou necessitavam de modificação; $\mathrm{e}$

- Os PCC foram listados numa tabela (QMS - esquema de monitoração da qualidade) contendo todas as informações necessárias para o seu controle (anexo 3).

Setores como laboratórios, técnicos e de gestão da qualidade deram apoio ao grupo de trabalho quanto ao fornecimento de informações conceituais referentes aos pontos levantados, bem como sugeriram alguns perigos que deveriam ser analisados, por serem conhecidos na literatura como inerentes àquele processo e/ou produto.

Biscoito é um produto que possui baixa atividade de água, logo oferece poucas condições para o desenvolvimento de microorganismos. Com base nos resultados observados, podese perceber que, analisando as etapas do processo de fabricação do produto, $90 \%$ dos pontos críticos de controle indicados estavam relacionados com a contaminação por corpos estranhos $\mathrm{e}$ as modificações sugeridas se concentraram na instalação de peneiras, ímãs, filtros e detectores de metais. O controle dos PCC garantiu a ausência ou a diminuição da presença de contaminação física, assim como o cumprimento das normas de higiene e comportamento sugeridas pelas BPF.

Como esperado, foi observado que, para a implantação do sistema HACCP, é fundamental que os empregados que atuam diretamente na fabricação estejam convencidos de que, fazendo controle sistematizado das etapas de fabricação indicadas como pontos críticos de controle, haverá uma diminuição das contaminações do produto e, conseqüentemente, um provável aumento da satisfação dos consumidores. 
Com o objetivo de sensibilizar os trabalhadores da fábrica, foram utilizados nos treinamentos relatos de consumidores que tiveram algum tipo de problema com a segurança do produto e também foi feita uma correlação entre a casa do empregado e o ambiente da fábrica, devendo-se manter em ambas idênticas atitudes quanto à segurança do alimento.

À medida que as modificações solicitadas iam sendo implementadas e existia uma maior exigência de mudança no comportamento para uma cultura voltada para a segurança do produto, percebia-se o comprometimento da alta administração com a implantação do HACCP.

Percebeu-se que, quando se estavam implementando as idéias novas da HACCP e das BPF, as pessoas ficavam desconfiadas em relação ao objetivo desses sistemas. Portanto, é muito importante que essas expectativas sejam esclarecidas e aqueles que trabalham nas funções de gerência tenham atitudes que sirvam de exemplo para todos, pois o comportamento dessas pessoas é bastante observado como evidência de comprometimento com a empresa.

A implementação do sistema de HACCP gerou um grande volume de documentação e uma preocupação com as suas atualizações. A documentação teve de ser rotineiramente revisada, principalmente no início da implementação (a cada 2 meses), pois alguns pontos, quando começaram a serem monitorados, tiveram a necessidade de ajustes nos seus limites de controle. Se essa sintonia não existisse, o sistema poderia ter sua confiabilidade compro- metida. Em seguida, essa atualização da documentação foi estendida para uma vez por ano.

Houve um acompanhamento do monitoramento dos pontos críticos de controle levantados pela HACCP, pois foi muito comum aparecerem formulários com erro no preenchimento, sem atendimento às normas estabelecidas no QMS (Esquema de Monitoramento da Qualidade) e sem a descrição das medidas corretivas tomadas.

O projeto de implementação da HACCP e das BPF começou em julho de 1997, tendo sido observado um decréscimo de $25 \%$ nas queixas dos consumidores por corpos estranhos em 1998 e 1999.

\section{Conclusão}

HACCP é uma importante método para se A fazer um estudo sistematizado dos perigos que podem comprometer a segurança do produto alimentício, pois tem uma atitude voltada para o controle preventivo ao longo do processo, ao invés da inspeção do produto final.

O treinamento e comprometimento de todos os envolvidos na fabricação, principalmente, e com destaque, a alta administração, são uma das condições básicas para o sucesso de implantação dessa ferramenta.

A HACCP, quando aplicado em conjunto com as BPF, apresenta melhor resultado, pois existe uma complementação de esforços para controlar os pontos que oferecem perigos de contaminação do produto. 


\section{Anexo 1}
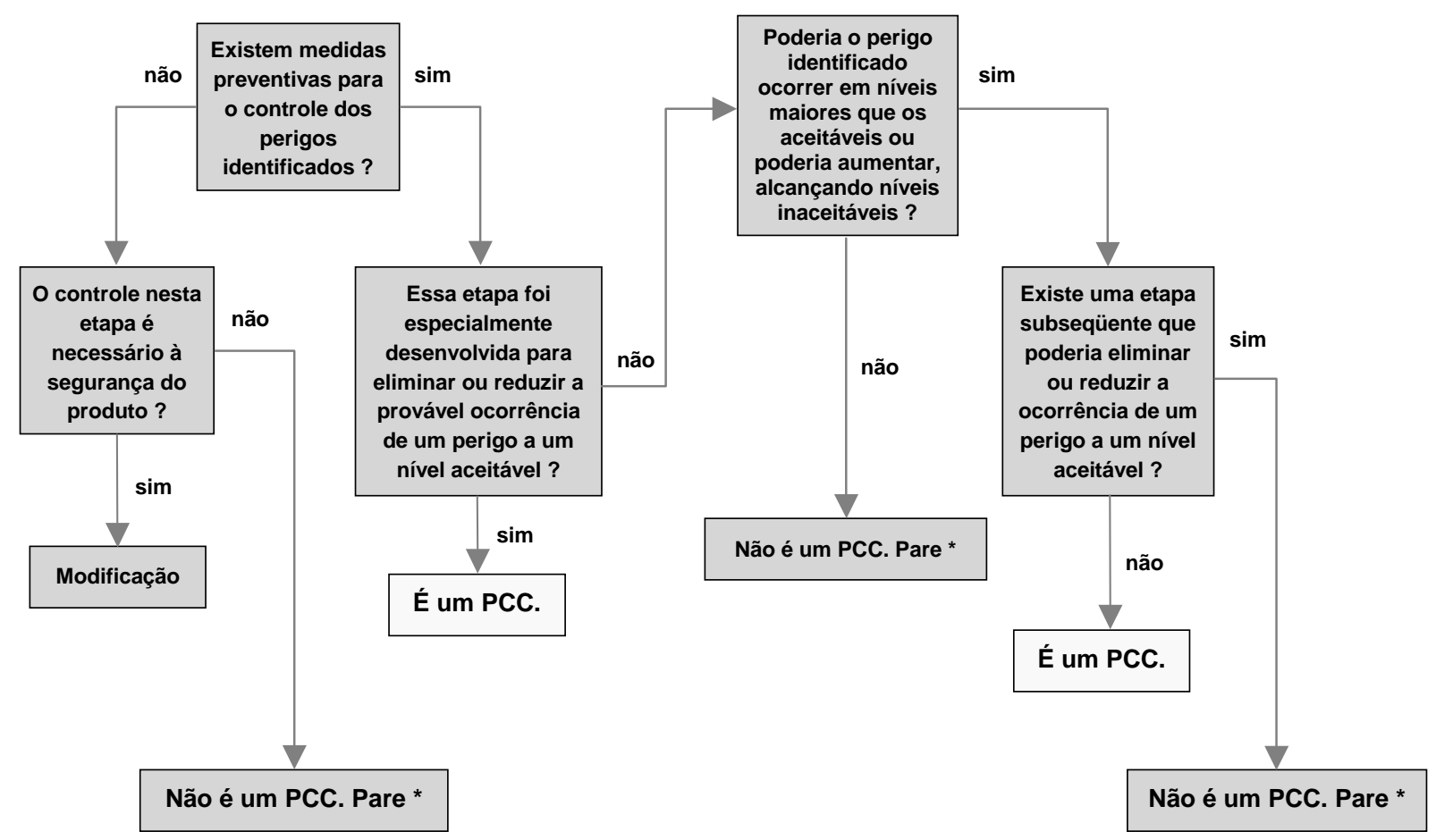

* Prossiga para o próximo perigo identificado no processo

Fonte: FAO / WHO

Anexo 2

\begin{tabular}{|c|c|c|c|}
\hline $\mathbf{N}^{\mathbf{0}}$ da BPF & Localização do PCC & $\begin{array}{c}\text { Perigo (que se pretende } \\
\text { eliminar ou reduzir) }\end{array}$ & Descrição da BPF \\
\hline 01 & $\begin{array}{c}\text { Equipamento de } \\
\text { mistura da massa }\end{array}$ & Fio de cabelo & $\begin{array}{c}\text { Usar touca na cabeça cobrindo todo o } \\
\text { cabelo e usar blusa de manga } \\
\text { comprida }\end{array}$ \\
\hline 02 & $\begin{array}{c}\text { Equipamento de } \\
\text { mistura da massa }\end{array}$ & Papel / papelão & $\begin{array}{c}\text { Ao abrir o saco de matéria-prima } \\
\text { observar para não rasgar o saco e cair } \\
\text { pedaço de papel / papelão na massa }\end{array}$ \\
\hline 03 & $\begin{array}{c}\text { Lona transportadora } \\
\text { de massa crua }\end{array}$ & Fio de algodão & $\begin{array}{c}\text { Observar se a lona está descosturando } \\
\text { ou soltando fios na lateral e em } \\
\text { seguida fazer o reparo }\end{array}$ \\
\hline 04 & $\ldots$ & $\ldots$ & $\ldots$ \\
\hline 05 & $\ldots$ & $\ldots$ & $\ldots$ \\
\hline
\end{tabular}




\section{Anexo 3}

\begin{tabular}{|c|c|c|c|c|c|}
\hline \multirow{7}{*}{ } & 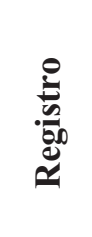 & 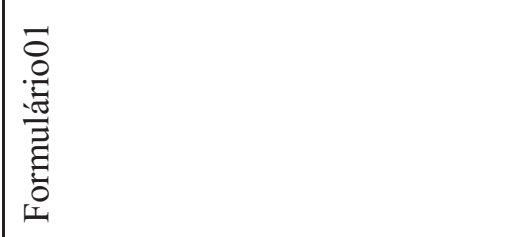 & 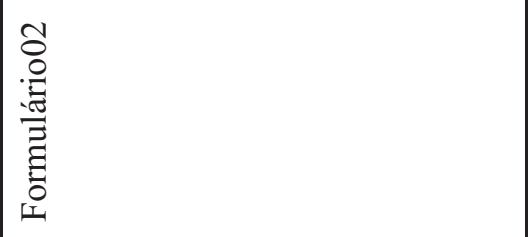 & $\vdots$ & \\
\hline & 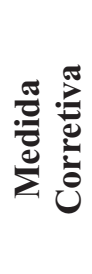 & 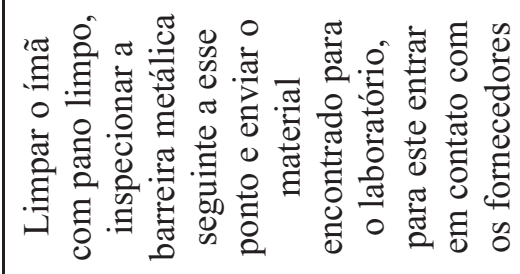 & 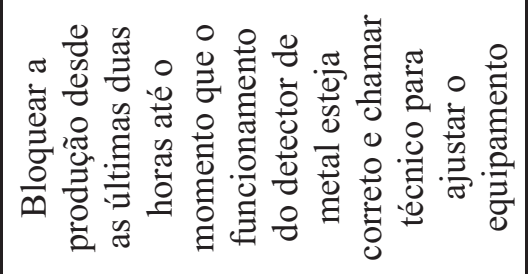 & $:$ & : \\
\hline & हूँ & 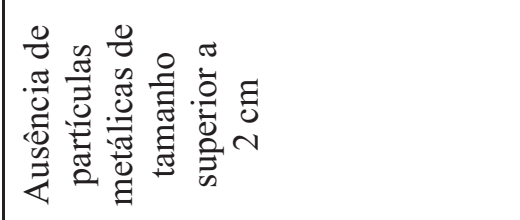 & 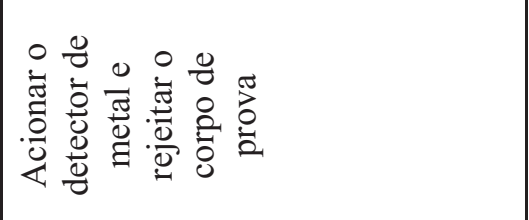 & $\vdots$ & $\vdots$ \\
\hline & ठ̊ & 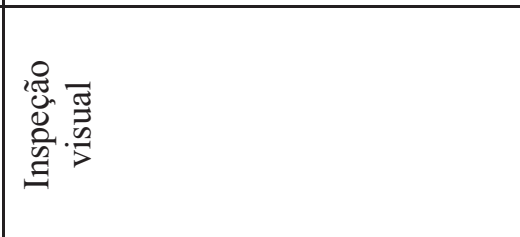 & 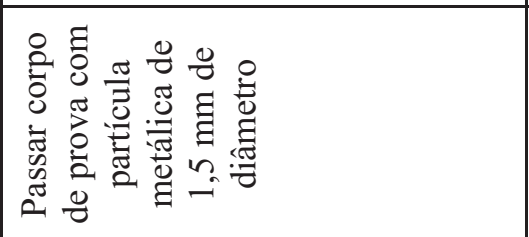 & $\vdots$ & $\vdots$ \\
\hline & 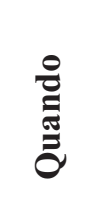 & 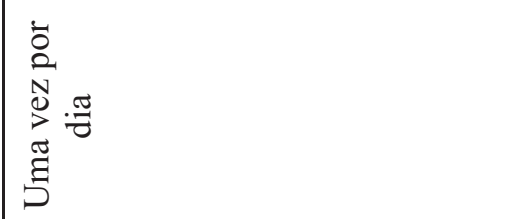 & 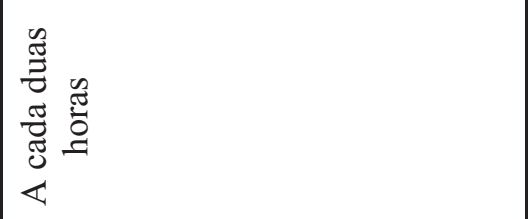 & $\vdots$ & $\vdots$ \\
\hline & $\stackrel{\Xi}{\Xi}$ & 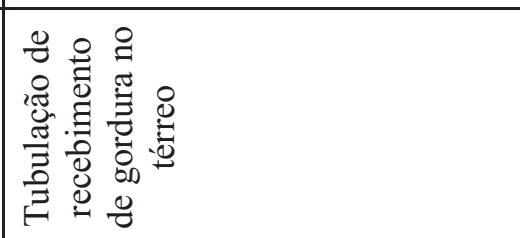 & 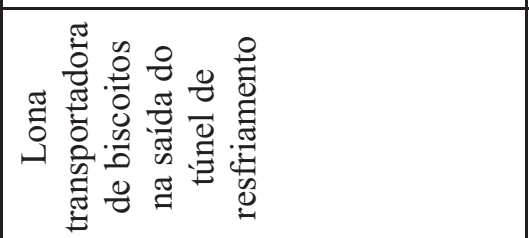 & $\vdots$ & $\vdots$ \\
\hline & छٍ̆ & 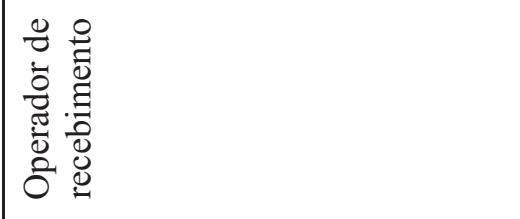 & 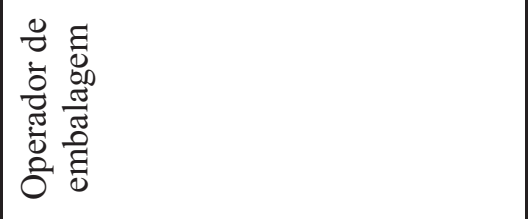 & $:$ & \\
\hline 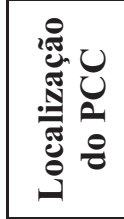 & & 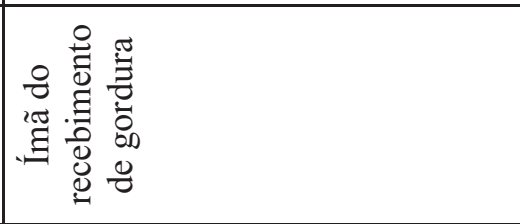 & 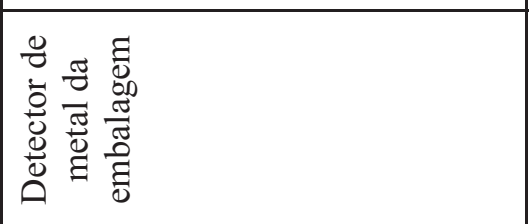 & $\vdots$ & \\
\hline $\begin{array}{l}80 \\
8 \\
i \\
i\end{array}$ & & $\bar{\sigma}$ & $\tilde{\delta}$ & ஜ̊ & J \\
\hline
\end{tabular}




\title{
Referências Bibliográficas
}

ATHAYDE, A.: "Sistemas GMP e HACCP garantem produção de alimentos inócuos." Engenharia de Alimentos, ano 5, no 23, janeiro/fevereiro, 1999.

BARENDZ, A.W.: "Food safety and total quality management." Food Control, vol. 9, n 2-3, 1998.

BENNET, W.L. \& STEED, L.L.: "An integrated approach to food safety." Quality Press, vol. 32, $\mathrm{n}^{\mathrm{o}} 2$, February, 1999.

BRANDIMARTI, L.: "Comer é questão de vida ou de morte." Banas Qualidade, junho de 1999.

BRITISH QUALITY FOUNDATION: Guidance for application of ISO 9000 in food and drink industry, 1999.

CARBALLIDO, J.R.; VIYELLA, A.R. \& MORENO, I.J.: "Exigencias de calidad en las empresas alimentarias: industria carnica." Alimentaria, Enero-Febrero, p. 23-26, 1994.

GRIJSPAARDT, V.C.: "HACCP in the EU." FoodTechnology, vol. 49 (3) 36, 1995.

ILSI (International Life Science Institute): A simple guide to understanding and applying the hazard analysis critical control point concept. $2^{\text {nd }}$ edition, 1997.

JOUVE, J.L.: "Principles of food safety legislation." Food Control, vol. 9, n 2-3, 1998.

JURAN, J.M. \& GRYNA, F.M.: Quality planning and analysis. Printed by MvGraw-Hill, $3^{\text {rd }}$ edition, United States of America, 1993.
OLIVEIRA, W.B.: "Qual é a certficação da sua empresa?" Banas Qualidade, maio de 1999.

PALADINI, E.P.: Gestão da qualidade: a nova dimensão da gerência de produção. Trabalho apresentado à UFSC como parte dos requisitos de concurso de professor titular na área de gerência de produção. 1996.

PETA, C. \& KAILASAPATHY, K.: "HACCP - its role in dairy factories and the tangible benefits gained through its implementation." The Australian Journal of Dairy Technology, vol. 50, November, 1995.

STRINGER, M.F.: "Safety and quality management through HACCP and ISO 9000." Dairy, Food and Environmental Sanitation, August, 1994.

STRINGER, M.F.: "Safety and quality management through HACCP and ISO 9000." Dairy, Food and Environmental Sanitation, vol. 14, n ${ }^{\mathrm{o}}$ 8, p. 478-481, August, 1994.

SURAK, J.G. \& SIMPSON, K.E.: "Using ISO 9000 standards as a quality framework." Food Technology, p. 63-65, December, 1994.

SURAK, J.G.: “The ISO 9000 standard - establishing a foundation for quality." Food Technology, November, 1992.

World Health Organization (WHO) - Food Safety Issues. "HACCP: Introducing the Hazard Analysis and Critical Control Point System." WHO/FSF/FOS/97.2, 1997.

\section{IMPLEMENTATION OF THE HACCP IN THE FOOD INDUSTRY}

\begin{abstract}
The Hazard Analysis Critical Control Point (HACCP) concept is a systematic approach to ensuring food safety. The method is based on several different principles of direct or indirect detection of contamination. The objective is to control food safety by analyzing the potential hazards, designing the system to prevent problems, involving the operators in decision making and documenting events. HACCP concepts should be applied together with Good Manufacturing Practices. This paper discusses the importance of HACCP in Biscuit Industry and what kind of contamination is a weak point in this product. The results indicated that there are several initial problems in implementing HACCP, however tangible benefits can be achieved through reduced customer complaints.
\end{abstract}

Key words: HACCP, control, food, safety and hazard. 